\title{
Research on Rural Environmental Governance in Remote Mountainous Area from the Perspective of Rural Revitalization - A Case Study of Q Village in Liuzhou, Guangxi
}

\author{
Li Lixuan ${ }^{1, a}$, Wang Tianyi ${ }^{2, b}$, Chen Yu'an ${ }^{3, c^{*}}$,Yang Shuxin ${ }^{4, d}$, Chang $\mathrm{Yi}^{5, \mathrm{e}}$, Zhao \\ Hongyi ${ }^{6, f}$
}

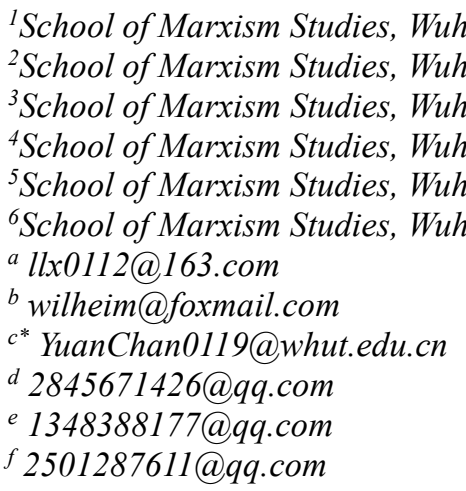

ABSTRACT

In the context of targeted poverty alleviation with great results and the gradual advancement of rural revitalization, environmental governance issues in remote mountainous rural areas still need to be resolved urgently. The centralization system of township governments, the absence of the functions of the two village committees, and the lack of village democracy are the main factors. To solve this dilemma, we need to play the role of Party organization, establish accountability mechanism and stimulate the subjectivity of villagers.

Keywords: environmental governance, garbage collection and transportation, rural governance

\section{乡村振兴背景下边远山区农村环境治理问题研究 - —以广西柳州 $Q$ 村为例}

李俐璇 $1, \mathrm{a}$ 王天翼 $2, \mathrm{~b}$ 陈昱安 $\mathrm{c}^{*}$ 杨舒心 $4, \mathrm{~d}$ 昌意 $5, \mathrm{e}$ 赵洪艺 $6, \mathrm{f}$

\footnotetext{
1 武汉理工大学马克思主义学院, 武汉, 湖北, 中国

2 武汉理工大学马克思主义学院, 武汉, 湖北, 中国

3 武汉理工大学马克思主义学院, 武汉, 湖北, 中国

${ }^{4}$ 武汉理工大学马克思主义学院, 武汉, 湖北, 中国

5 武汉理工大学马克思主义学院, 武汉, 湖北, 中国

6 武汉理工大学马克思主义学院, 武汉, 湖北, 中国

allx0112@163.com

${ }^{b}$ wilheim@foxmail.com

$c^{*}$ YuanChan0119@whut.edu.cn

d2845671426@qq.com

e1348388177@qq.com

f2501287611@qq.com
} 


\section{摘要}

在精准扶贫取得巨大成效, 乡村振兴逐步推进的大背景下, 边远山区农村的环境治理问题仍亟需解决, 乡镇政 府的一元化体制、村两委职能缺位和村民主体性不强是主要原因, 破解该难题, 就需要发挥党组织作用、建立 问责机制和激发村民主体性等路径发挥作用。

关键词: 环境治理, 垃圾收运, 乡村治理

\section{1. 前言}

作为一年里党和国家针对农村工作起到提纲挚 领作用的 2021 年中央一号文件《关于全面推进乡村 振兴加快农业农村现代化的意见》（下简称“一号文 件”) 和新鲜出炉的“十四五”规划《中华人民共和国国 民经济和社会发展第十四个五年规划和 2035 年远景 目标纲要》 (下简称“纲要”) 均将农村环境治理放在 重要位置, 作为环境治理的重要部分, 生活垃圾的处 理一直是重点难题, 只有解决生活垃圾治理问题, 才 能推动乡村振兴, 促进“美丽乡村”建设的稳步推进。

\section{2. 个案描述: 广西柳州 $\mathbf{Q}$ 村的环境治理结构 变迁}

\section{1. 案例背景与概述}

$\mathrm{Q}$ 村位于广西壮族自治区柳州市某省级贫困县 (注: 2020 年 5 月, 该县退出贫困县序列), 地处九 万大山腹地的河谷农业气候区, 平均海拔 200 米, 冬 短夏长, 雨水充沛。全村共有 11 个村民小组, 463 户, 总人口 1672 人, 耕地面积 1080 亩, 山林面积 4.48 万 亩。城镇化背景下, 大批青壮年外出务工, 进入广东 地区的劳动密集型产业。村内常住人口大幅减少, 老 年人口和中年妇女承担起了生产任务, 活动范围日益 萎缩, 全村耕地抛荒面积近 30\%, 山地抛荒面积近 $20 \%$ 。选取该村庄的原因是：（1）主要生产活动为水 稻种植和林木栽培, 产业结构相对单一; (2) 村内常 住人口总量长期保持稳定, 生活废弃物种类与数量波 动较小; (3) 村庄建制完全, 环境问题长期未能对得 到解决, 分析现状有助于解决本研究的问题。

在实行村落垃圾治理政策前, 村民普遍缺乏环保 意识, 垃圾被随意丢弃在道路两旁, 或是堆放至河边, 让流动的溪水带走垃圾, 大量农业废弃物导致了严重 的面源污染, 对农村生态系统造成了极大破坏, 村庄 垃圾整治行动势在必行。因为村集体能力有限, 2013 年由镇政府出资, 在 Q 村的每个自然屯建起了 1-2 个 垃圾集中焚烧灶, 授意村集体任命了数名环卫专员, 之后 (2015) 又在各屯的集中居住点配置了不同数量 的垃圾桶。在上级的物质支援下, 村庄整体的垃圾收

\section{运情况有所好转。}

好景不长, 村庄的环境状况又因各种因素而恶化, 比较突出的就是村庄道路工程的开展: 上世纪末, 镇 政府拨款启动了 $\mathrm{Q}$ 村的道路工程。道路修建产生的大 量松软泥沙进入河道, 河床逐渐抬升, 地表水减少, 河水变得越来越浑浊。一方面, 河流流速降低, 流量 减少, 河中废弃物堆积, 散发恶臭; 另一方面, 河床 与岸边的高度差相对变小, 每逢汛期, 水流携带各类 垃圾冲入农田, 淹泡作物, 影响收成。村中缺少大型 机械, 清理起来十分困难。2018 年, 某屯曾提出拓宽 小渠、建成大沟的想法, 但各方主体不停推卸责任, 最后该方案无疾而终。

\section{2. 混乱治理循环}

$\mathrm{Q}$ 村垃圾处理方式共有两种: 一是就地焚烧, 二 是由镇政府派出垃圾清运车进村收运。通往 $\mathrm{Q}$ 村的道 路崎岖, 居民点分散, 车辆入村较为困难。而在国道 附近交通便利的村庄, 则定期会有车辆将垃圾运送出 村。面对运力不足的问题, 村庄只能选择采用焚烧的 方式，但是焚烧垃圾早已是被各层级的政府所禁止的 行为, 但不采取此种方式, 又没有定期的清运车辆, 如果对垃圾进行随意填埋, 同样会对土地造成严重污 染, 危害甚至比焚烧更大。综合这些情况, 上级政府 对于 $\mathrm{Q}$ 村现有的垃圾处理方式持默许态度。

与焚烧矛盾同时存在的, 是硬件设施的老化和损 毁。之前由镇政府拨款建设的炉灶和垃圾桶不少已毁 坏, 即使是未被损坏的炉灶, 大多也已堆满灶灰。若 未得到及时清理, 就会被从中找食的家畜扒拉散开, 使路面变得极其脏乱，影响美观。村民已向村集体多 次反映, 村集体在去年也向镇政府提交过重做申请, 但现在还未收到答复, 目前, 群众只能通过提高焚烧 速度、增加焚烧次数等方式自行消化。垃圾焚烧过后 剩下大量灶灰, 其中包括玻璃、铁片等尖锐物品, 不 能流入农田作肥, 清洁工便将其倒入河中, 农村垃圾 收运工作中的混合处理不仅带来了巨大浪费, 最终依 旧造成了严重的面源污染。

随着人们生活水平的日渐提高, 生活垃圾的种类、 数量增加, 也带来了新的难题: 尼龙制品、果皮菜叶、 
玻璃瓶罐、婴儿尿不湿这几类不可燃垃圾增多，既无 法变卖, 占地面积又大, 只能在固定地点统一堆放, 等待上级政府派下来的清运车将其处理。Q 村所在县 一级或更高级别政府每年都会不定时下村巡查环境 情况, 主要是检查村屯路口和焚烧灶附近是否有明显 垃圾, 河道是否干净整洁。为了应付检查, 镇政府会 拨款安排镇上的垃圾车驶进村中, 将沿路的垃圾都清 运出村。其他时间段, 镇政府每年还会派遣垃圾车入 村清理一到两次。类运动式的治理无法将环境整治常 态化, 长此以往村庄还是处于“治理-缓解-混乱-治理缓解”的循环逻辑中无法脱身。

\section{3. 制度乏力}

也有人曾经试图从制度方面寻找突破口, 将环境 治理常态化, 却同样困难重重: 一方面, 我国现行的 环保法律法规与环保标准主要是基于防治与治理城 市和工业的点源污染而制定的, 对于农村环境治理的 的规定太过笼统, 缺乏可操作性和科学性。镇政府对 村庄的垃圾收运工作没有任何成文规定和硬性要求, 任命的清洁人员仅承担着垃圾焚烧任务, 公路及河道 内垃圾收拣并不属于职责范围; 另一方面, 基层治理 主体在探索农村环境治理制度设计的道路上, 存在着 不少脱离农村实际的问题。为了让财政支出更为透明, $\mathrm{Q}$ 村所在镇政府在去年建立起了规范的工资上卡制 度, 要求村屯的清洁人员一并执行此项规定。上了年 纪的清洁工认为制度太过繁琐复杂, 索性不再接管事 务, 这给村干部的工作带来了不小的麻烦。经过村委 各方沟通, 镇政府最终决定每月先将这笔款项统一打 给村委副主任, 再由副主任给清洁工发放现金。

\section{4. 人力之忧}

$\mathrm{Q}$ 村的环卫专员任命通常由镇政府下发指标, 村 委组织各屯屯长选择生活困难、年龄较大、责任感较 强的村民从事这一岗位。如果招募不到足够人手，村 委还会下到屯里了解情况，做通清洁人员的思想工作。 但不少村民经过劝说仍然拒绝。目前, 村里超过半数 的清洁工由本屯屯长兼任。

问及原因, 无疑是这份工作的条件过于艰苦: 薪 酬极低, 没有工具配给和安全设备, 不少清洁工提到 自己曾在工作过程中由于产生的浓烟及废弃物爆炸 导致呕吐和受伤。且 $Q$ 村对于村内的垃圾处理工作没 有任何成文规定, 工作时间、频率以及强度依据个体 责任感自行安排, 这对清洁人员来说更像是一份可有 可无的兼职。之前曾有由于清洁人员工作间隔过长, 垃圾大量堆积，村民向村委进行投诉的例子。

“脱贫摘帽”冲刺阶段，上级政府对村容村貌的检 查较为频繁。如果验收期内垃圾堆积过多, 村委会给 村里的几名低保户支付每天一百元的薪酬, 让他们进 行突击清理。此外, 在“脱贫攻坚月”时期, 村委还针 对村里的贫困户开展了“公益岗”的活动, 给予一定补 贴, 让他们负责一些清洁乡村、道路维修项目, 据此
开展了一次全村大清洁, 效果显著。但活动结束后, 相关岗位的垃圾清理工作也随之暂停了。

对于资金拮据的村委班子而言, 开展村内的生活 垃圾治理更像是一种扶贫手段。他们借此机会, 为村 内的困难群众提供岗位, 使其能够获得一定的额外收 入, 达到事半功倍的效果。但在治理体系中扮演着重 要角色的他们, 同时也面临着较为滥地的处境: 面对 上级直管单位，他们无法拿到足够的项目资金，治理 工作也不符合统一的环境标准; 面对承担的清洁任务, 他们招募不到足够的人手，就连现有员工的薪金待遇 也难以保证——截止 2021 年 2 月，由于县政府资金 短缺, 村委已有三个月没有给清洁人员下发垃圾处理 费用。“村民委员会这一建立在农村广大土地上的村 民自治组织并没有真正发挥自治功能......这种'政府 不愿管,村委会管不了'的局面,造成治理主体的缺位， 使得农村环境污染的治理成了一个没有实体支撑的 制度空壳。”当下他们能做的, 只有尽可能地培养村民 的环保观念与垃圾处理意识, 减少生活垃圾治理过程 中的阻碍。

\section{5. 宣传与大环境的改变}

垃圾治理成为村庄环境治理的首要任务, 村委班 子既有对垃圾分类和定点丢弃行为的公告栏式宣传, 也会在村委大会和日常聊天中对村民进行呼吁倡导。 除宣传因素外, 青年人口素质的提升也是村里环境状 况改善的原因之一, 他们对公共环境保护的重视程度 日益增强。物质条件的改善，使得村民开始逐步关心 公共环境问题。如今, 大部分村民都会自觉将垃圾带 到焚烧灶旁等待清洁工处理, 而不是丢弃至河边, 看 到有人违反也会及时出言制止。村容村貌持续美化, 水质状况也有所提升。但村里常住人口中, 近 $60 \%$ 为 五十岁以上、思维相对固化的中老年群体, 他们时常 无视村干部的劝阻, 继续随地乱扔, 针对这种情况, 村民们也只能以劝导为主, 求得一个缓慢转变。可见, 农村生活垃圾乃至整个生态系统的治理是一个漫长 的过程，不管是硬件设施，还是制度文化，亦或者是 群众的转变, 都需要一步一步耐心的引导和精心的策 划, 以求突破长期困扰在 $\mathrm{Q}$ 村的环境难题。

\section{3. 问题分析}

\section{1. 乡镇政府: 一元化体制}

步入新时代，党和国家高举“生态文明建设”旗帜， 引领“美丽中国”建设，推动建成生态宜居的美丽乡村， 并在实践中逐步形成政府主导型环境保护模式。诚然, 政府主导村庄生态建设是社会主义制度下乡村建设 的应有之义。然而, 实践中, 广西政府主导下的一元 化、压力型治理模式成为乡村环境治理失灵的元凶。 究其原因, 一方面, 科层体系下, 任务层层发包, 在 政绩与指标的双重压力下，农村垃圾治理沦为“政治 性”任务。财政、资源有限前提下，易于见效的物理性 
处置成为应付上级部门高频检查的最优选，乡村垃圾 治理演变为压力型“运动式”治理, 陷入“面子工程”的 图圍, 乡村生态建设面临常效性与长效性困境。另一 方面，政府主导型环境保护的广西模式呈现出明显的 “一元化”特征, 即乡镇政府作为唯一外部行为主体, 直接干预农村垃圾处置业务。广西模式下，现有的政 府一元体制伴随着巨大的行政压力和高昂的治理成 本, 为当地政府带来人员配置与财政上的负担。这一 治理模式与当前我国倡导建设“社会本位”的“服务型 政府”理念相悖。对此, 2018 年召开的全国生态环境 保护大会上, 李克强总理指出, 生态环境保护须“协同 发挥政府主导和企业主体作用”, 明确了生态环境保 护中的权责划分，为广西农村垃圾治理事务开出“多 元治理”的处方。

此外，虽然在“乡村振兴”战略的深化推进下，“美 丽乡村”建设得到党和国家的高度关注, 但对于刚刚 “脱贫摘帽”的乡镇而言, 巩固脱贫成果、防止返贫才 是当前乡镇工作的重中之重。乡镇领导普遍重视经济 发展的硬指标, 而忽视乡村生态环境建设的重要价值。 因此，从近年公布的政府财政预算来看，环境卫生整 治费用只占冰山一角，而垃圾治理费用更是微乎其微。 乡镇领导相对滞后的环保意识造成垃圾治理预算资 金微薄, 政府主导型整治模式则产生高昂的治理成本, 两者间的矛盾使得 $\mathrm{Q}$ 村的垃圾整治工程深陷恶性循 环。

\section{2. 村两委: 自治职能缺位}

作为农村垃圾治理的直接行为主体, $Q$ 村村委会 正面临“权轻责重”的困境。行政权上, 村委会组织法 将村委会定性为: “农民自我管理、自我教育、自我服 务的基层群众自治组织”, 并规定“乡、民族乡、镇的 人民政府对村民委员会的工作给予指导、支持和帮 助。”然而, $Q$ 村垃圾治理实践中, $Q$ 村所在乡镇与村 委会构成事实上的领导与被领导关系, 乡镇直接干预 村庄垃圾治理事物, 削减村委会环境污染治理的自主 权。压力型治理体系下, 村委会甚至异化为乡镇政府 应付检查的工具。组织架构上, 村委会组织法规定村 委会对于生态环境保护的职责在于“教育村民合理利 用自然资源, 保护和改善环境。”并未在村委会下设主 管生态建设的专职委员, 垃圾治理事宜也未纳入村民 会议议题中, $\mathrm{Q}$ 村村委会主持垃圾治理工作缺乏人员 配备和组织架构的保障, 专业化水平存疑。此外, 十 八大以来, 随着全面从严治党向基层延伸, 农村基层 党组织和党员干部成为乡村自治的“主心骨”, 也成为 了乡村生态建设的“排头兵”。然而, 在 $\mathrm{Q}$ 村垃圾治理 实践中，基层党支部和党员干部怀有“搭便车”的侥幸 心理, 不愿做垃圾治理的“领头羊”, 相互推诿, 责任 缺位。Q 村的垃圾治理事务由于缺乏主事人的规划和 领导, 最终化作一盘散沙。

\section{3. 村民：主体性困境}

梁漱溟曾说: “农民自觉，乡村自救，乡村的事才 有办法”。然而, Q 村垃圾整治现状表明, 农民在乡村 垃圾治理中面临主体性困境。政府主导型模式下, 乡 镇政府依据政策宣传的垃圾转运等“科学化治理”手 段脱离 $\mathrm{Q}$ 村现实, 默认“垃圾焚烧”的处理方式则忽略 了农民生产和生活所需。然而, 村民作为乡村人居环 境治理的重要参与主体，农村环境治理问题与其生产、 生活关系紧密, 任何忽视生产和生活需求的整治行动 都不可能得到村民的支持。此外，任务层层下放的压 力型治理体系下, $\mathrm{Q}$ 村的垃圾治理行动异化, 由技术 性治理转向选择性治理, 治理目的也由根除污染转为 应付检查, 且垃圾处理方案基本取决于官员和技术专 家的取向偏好，高度行政化倾向使得村民对乡村垃圾 治理产生“局外人”心态。某种程度上, 脱离现实的治 理政策和高度的行政化倾向是造成 $\mathrm{Q}$ 村垃圾治理中 村民主体性困境的主要外部因素。

马克思主义认识论指出, 意识具有能动性, 对物 质具有能动的反作用。Q 村垃圾治理中, 村民自身价 值观念作为内因直接决定其主体作用的发挥。一方面, 经济相对落后的 $\mathrm{Q}$ 村村民不仅在经济地位上处于劣 势，同时也面临文化知识的结构性挑战。村民的参与 冷漠首先源于其淡薄的生态理念, 一度挣扎在贫困线 的农户普遍关心物质生活水平的提高和民生状况的 改善, 对于环境治理关注度低, 生态文明建设成果获 得感差, 缺乏对村庄垃圾整治任务的主体意识。另一 方面，村民对于本村垃圾治理项目的支付意愿低，支 付能力薄弱。在乡镇政府财政有限, 社会投资眪乏的 情况下，垃圾治理的“最后一公里”难题有赖于村民间 的有机衔接, 需要村民投入一定的时间、人力、金钱 成本, 共同参与到垃圾处置的各环节中。然而, 部分 村民出于“理性经济人”心态, 着眼当下经济利益的最 大化, 忽视了生态效益的持续性和长久性。而部分意 识到垃圾治理重要意义的村民却常因经济窘迫, 有心 无力, 难以积极参与。

\section{4. 对策分析}

随着全面扶贫工作的胜利结束, 党和国家在农村 工作方面的工作重心转向了防止返贫和提高乡村人 民群众生活质量上来, 提高乡村环境质量, 建设美丽 宜居乡村一直是乡村治理的一个重要部分, “纲要”明 确指出在“十四五”期间要“开展农村人居环境整治提 升行动, 稳步解决“垃圾围村”和乡村黑臭水体等突出 环境问题”, “深入开展村庄清洁和绿化行动, 实现村 庄公共空间及庭院房屋、村庄周边干净整洁”, 笔者基 于国家政策指引和样本村落现实情况提出了以下几 点对策建议:

\section{1. 党建引领，健全“三治结合”体系}

2021“一号文件”指出要“加强党对 “三农工作”的 全面领导”, 党组织在村中的作用日益突出, 实现党组 
织建设在村庄建设中的引领作用, 是实现乡村“善治” 的必要手段。村庄环境治理是一个系统性工程, 需要 有人站在全局的角度实现流程控制, 同时也要有真抓 实干的力量推动进程, 党组织通过充分发动支部现有 党员同志、教育吸纳先进分子加入党支部等手段产生 正向激励, 以求形成示范效应, 以点带面, 在发挥党 支部“战斗堡垒”作用的同时带动全体村民投入到环 境整治的工作中, 一边实现党支部的教育功能, 一边 充分发挥党员的先锋模范作用, 在打造美好环境的进 程中释放“红色能量”。

仅仅发挥人的力量不足以达成目标, 还需要体系 和制度的协助。首先是发挥居民自治的作用, 让村民 自己决定工作流程的走向, 在环境整治工作中更富踏 实感; 二是深入开展法治宣传教育, 提高村民的法律 意识和规则意识, 根据本村实际情况修订村规民约, 将环境治理放在制度的框架下进行, 避免不规范的 “出位”和“失位”; 三是单纯的法律规则不是一个村庄 运行的全部倚靠, 还有很多的“潜规则”穿插其间, 所 以在乡村环境治理的工作中必须要特别重视“德治” 的作用, 在环境治理工作中注重释放道德力量, 将法 律规范的冰冷巧妙地转化成乡土社会的脉脉温情, 降 低环境治理在实际操作中的摩擦成本。

\section{2. 健全问责机制, 探索切合实际的环境治理 新模式}

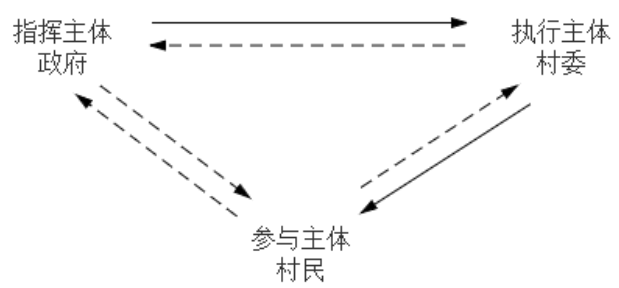

图 1 机制转变前各环境治理主体的低效互动模式

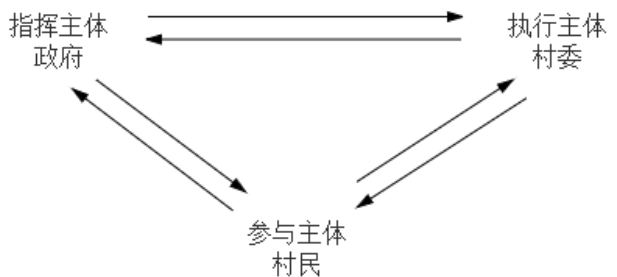

图 2 机制转变后各环境治理主体的良性互动模式

农村环境保护工作与生产条件改善、村容村貌改 变、生活质量提高息息相关, 破解农村的环保困境是 政府应有之义。只有将政府的环境责任转变为一种常 态机制, 将环保工作纳入干部考核体系, 提高对政府 的问责力度, 才能让政府的环境责任落到实处, 从而 为解决农村环境问题提供重要的政治和法律保障。

传统的政绩观念, 明确政府责任中对环境保护的 刚性要求, 为提高治理效率, 可通过适当放权等方式, 调整村镇两级的财权和事权, 将基础性的环境治理工 作交由更熟悉村落状况的村委班子; 另一方面, 村委 班子要将环卫工作纳入日常事务, 扮演好基层群众与
上级部门之间的“传声筒”角色, 主动接受群众监督, 加大宣传力度, 动员广大群众积极参与农村环境整治 工作。村镇两级加强上下联动, 形成整体合力, 共同 完成“消极行政”模式向“积极行政”模式的转变, 实现 乡镇管理与村民自治的良性互动。

\section{3. 发挥居民主体性作用, 依靠社会资本促进 环境治理}

“社会资本”这一概念的定义学界尚有争议，相对 认同度高一点的解释为社会资本是学者帕特南在 1993 年提出的“社会资本是指社会组织所具有的特性, 如信用、社会规范和社会网络等。其将能提高社会效 率”。尽管历经巨大变迁, 以样本 $\mathrm{Q}$ 村代表的部分中 国乡村保留着“熟人社会”的特征, 道德和亲缘仍旧是 村民们为人处世的重要靠量依据, 复杂的社会网络和 成熟的社会规范中蕴含着丰富的社会资本，推进乡村 环境治理, 这是一种值得重视并且加以利用的资源。

上文提到，村民层面存在着主体性缺位的问题， 而解决问题的关键在于激发村民活力, 促进其主观能 动性的实现, 为了达到这一目标, 在实现治理的过程 中就要因地制宜，根据所在村庄的历史文化特性，利 用好风俗习惯、伦理道德在村民行为取向中的规范作 用。具体措施可以以亲缘为依据, 建立治理单元, 相 互监督, 相互促进, 村集体和党组织适时以物资发放 或精神表彰的方式施以激励, 树立在环境自治方面的 模范典型, 在互相信任的基础上形成紧密的治理共同 体, 并通过依托在风俗习惯上的宣传方式等有意识地 塑造新的生活风尚，增强环境保护在村民心中的认同 感和行为取向上的约束力。

\section{5. 结论}

总的来看，在该地区农村经济发展水平大步迈进 的同时, 生态保护工作却不断掉队。环境问题持续存 在，人居环境长期得不到有效改善。要快速补齐农村 环境治理短板，必须充分激发乡村系统中各主体的内 生动力, 凝聚治理合力, 妥善处理经济发展与生态保 护之间的关系，搭建起科学长效的治理架构。切实弘 扬生态文明, 建设美丽乡村, 不断攻坚克难, 争取早 日实现乡村振兴战略的伟大胜利。

\section{项目基金}

本文为 2021 年全国大学生节能减排社会 实践项目与科技竞赛立项项目《农村生活垃圾 收运及治理优化调查一以柳州市融安县为 例》(414-3120600201)的阶段性成果之一。

\section{REFERENCES}

[1] Jia, F., Liu, J. (2014) Analysis on the role contradiction of township government in 
environmental protection. Theoretical Exploration, 02:74-77.

[2] Yu, K., Liu, J. (2011) Path choice of rural environmental governance:Cooperative governance and government environmental accountability. Truth Seeking, 12:105-107.
[3] Putnam, R., Leonardi, D. (1994) Making Democracy Work: Civic Traditions in Modern Italy. Contemporary Sociology, 26:306-308.

[4] Chinese government website. (2018) Xi Jinping attended the National Conference on ecological environment protection and delivered an important speech.http://www.gov.cn/xinwen/2018-

05/19/content 5292116.htm 